\title{
Mikrobiyom ve mikrobiyota
}

\section{Microbiome and microbiota}

Behice Kurtaran

Çukurova Üniversitesi Tıp Fakültesi, Enfeksiyon Hastalıkları ve Klinik Mikrobiyoloji Anabilim Dalı, Adana, Türkiye

\section{Öz}

Mikrobiyom ve mikrobiyota sıklıkla birbirlerinin yerine kullanılan ve insan vücudunda bulunan kommensal, simbiyotik ve patojenik mikroorganizmaların topluluğuna verilen isimdir. İnsan vücudunda mikroorganizmalar gastrointestinal sistem, orofaringeal alan, deri, hava yolları, ürogenital sistem, kan ve gözlerde lokalize olmuştur. Gastrointestinal mikrobiyomun koruyucu, metabolik ve yapısal etkileri söz konusudur. İntestinal mikrobiyota dengesi, immün regülasyonu sağlayan mikrobiyal kompozisyonun dengede kalması ile yani simbiyoz ile sağlanır. Eğer mikrobiyota çeşitliliğinde azalma, değişiklik ya da bozulma olursa -ki bu disbiyoz olarak adlandırılır- alerji ve inflamasyonla giden immün disregülasyon meydana gelir. Yani insan sağlığının idamesinde gastrointestinal mikrobiyotanın klinik önemi büyüktür. Kardiyovasküler hastalık, obesite, tip 2 diyabet, non-alkolik yağlı karaciğer hastalığı (NAFLD) ve bazı kanser tipleri ile disbiyoz arasında ilişki olduğunu gösteren çalışmalar mevcuttur.

Anahtar Sözcükler: Mikrobiyom, mikrobiyota, simbiyoz, disbiyoz.

\begin{abstract}
Microbiome and microbiota are commonly used interchangeably and are the name given to the community of commensal, symbiotic and pathogenic microorganisms found in the human body. Microorganisms in the human body are localized in the gastrointestinal tract, oropharyngeal area, skin, airways, urogenital system, blood and eyes. There are protective, metabolic and structural effects of gastrointestinal microbiome. Intestinal microbiota balance is achieved by maintaining the equilibrium of the microbial composition that provides immune regulation, i.e. symbiosis. If microbiota diversity decreases, changes or deteriorates, which is called dysbiosis, immune dysregulation leading to allergy and inflammation occurs. In other words, gastrointestinal microbiota has great clinical importance in the maintenance of human health. There are studies showing a relationship between dysbiosis and cardiovascular disease, obesity, type 2 diabetes, non-alcoholic fatty liver disease (NAFLD) and certain types of cancer.
\end{abstract}

Keywords: Microbiome, microbiota, symbiosis, dysbiosis.

Mikrobiyom ve mikrobiyota sıklıkla birbirlerinin yerine kullanılan ve insan vücudunda bulunan kommensal, simbiyotik ve patojenik mikroorganizmaların topluluğuna verilen isimdir. İnsan vücudu $10^{13}$ hücreden oluşurken, $10^{14}$ mikroorganizma barındırmaktadır (1). Bin beş yüzden fazla bakteri türü olduğu bildirilmektedir. Bu da insanın kendi hücre sayısının 10 katı fazla mikroorganizma varlığı demektir ve üstelik bu hesapta virüsler bulunmamaktadır. Mikrobiyomun ağırlığının insan beyninden ağır olduğu ve insan genomundan en az 100 kat (250 kat olarak bildirilen yayınlar da vardır) fazla olduğu, 8 milyon farklı gen barındırdığı bildirilmektedir (1-3).

Insan mikrobiyom projesi (human microbiome project=HMP) hedefleri aşağıda özetlenmiştir (23):

- İnsan vücudundaki tüm mikroorganizmaları belirlemek

- İnsanlar arasındaki mikrobiyom farklııılarını saptamak

Yazışma Adresi: Behice Kurtaran

Çukurova Üniversitesi Tıp Fakültesi, Enfeksiyon Hastalıkları

ve Klinik Mikrobiyoloji Anabilim Dalı, Adana, Türkiye

E-posta: behicekurtaran@gmail.com 
- Insan mikrobiyom değişikliklerinin hastalıklarla ilişkisi olup olmadığını anlamak

- Mikrobiyom saptanmasında kullanılacak yeni biyoinformatik program ve yaklaşımların geliştirilmesini sağlamak

- Bunları yaparken etik ve sosyal değerlere özen göstermek

HMP 2007 yilında NIH (National Institute of Health) tarafından başlatıldı. Üç yüz gönüllünün beş vücut bölgesinden 11700 örnek elde edildi. Bu proje ile insan vücudunda 10000 kadar bakteri ve mantar türü saptandı. Bunu takiben yeni mikrobiyom projeleri başlatıldı ve hayvanlar ve diğer ekolojik çevreler de kapsama alındı (4).

İnsan vücudunda mikroorganizmalar gastrointestinal sistem (\%29), orofaringeal alan (\%26), deri $(\% 21)$, hava yolları $(\% 14)$, ürogenital sistem $(\% 9)$ ve kanda (\%1) lokalize olmuştur (4-5).

Gastrointestinal mikrobiyomun koruyucu, metabolik ve yapısal etkileri söz konusudur (4).

\section{Koruyucu etkiler:}

- Patojen mikroorganizmaların uzaklaştırılması

- Besinle yarışma

- Reseptörle yarışma

- Antimikrobiyal faktörlerin üretimi

\section{Yapısal etkiler:}

- Mukozal bariyeri güçlendirme

- IgA indüksiyonu

- Sıkı bağlantıların (tight junction) sıkılaştırılması

- İmmün sistem gelişimi

\section{Metabolik etkiler:}

- Epitelyal hücre diferansiyasyonunun ve proliferasyonunun kontrolü

- Diyetsel karsinojenlerin metabolizması

- Vitaminlerin sentezi

- Sindirilemeyen gıda artıklarının epitel kaynaklı fermentasyonu

- pH'nın düşürülmesi

- Biliyer asit metabolizmasının düzenlenmesi

- İmmün sistem maturasyonu ve gelişimi

- Kısa zincirli yağ asitlerinin (SCFA) üretimi

Mikrobiyomun yüksek bir metabolik kapasitesi mevcuttur. Glikozid hidrolaz üretimi ve glikanın kullanılabilir şekerlere dönüştürülmesini sağlamaktadırlar. İnsan genomunda kodlanmış böyle bir enzim yok iken, bakterilerde mevcuttur.
Böylelikle sindirdikleri karbonhidratlardan kısa zincirli yağ asidi (SCFA) oluştururlar. SCFA'lar kolon epitelinin majör enerji kaynağıdırlar ve erişkinlerin enerjilerinin \%10-15'ini sağlamaktadırlar (6-7).

SCFA'ların metabolik etkileri mukozal dolaşımı arttırmak, mukozaya enerji desteği vermek, rezeksiyon işlemlerinden sonra iyileşmeyi sağlamak, intestinal hücre proliferasyonunu arttırmak, su ve sodyum emilimini uyarmak, mukus yapımını arttırmaktır (8-9).

Esas gastrointestinal mikrobiyotada 5 grup (filum; bölüm) ve 1500 'den fazla tür mikroorganizma bulunmaktadır (2-3):

1. Bacteroidetes

2. Firmicutes

\section{Actinobacteria}

4. Proteobacteria

\section{Cerrucomicrobia}

Bacteroidetes (\%9-42) ve Firmicutes'lerin (\%1431) toplamı, mikrobiyatanın çoğunluğunu oluşturmaktadır. Firmicutes'ler 16srRNA dizi analizine göre Bacilli, Clostridia, Erysipelotrichi olarak üç sınıfa ayrılmaktadır. Clostridia sınıfı ise Clostridiales, Halanaerobiales ve Thermoanaerobacterales takımlarından oluşmaktadır. Clostridiales takımının en önemli ailelerinden biri Peptostreptococcaceae ailesidir. Bacteroidetes filumunun içinde yer alan Bacteroidaceae ailesi içinde Bacteroides, Porphyromonas, Prevotella, Leptotrichia ve Fusobacerium genusları (cins) vardır. Firmicutes'ler Gram pozitif, Bacteroidetes'ler Gram negatif anaerop bakterilerdir.

Insan mikrobiyotasında bakteriler yanında çoğunluğunu bakteriyofajların oluşturduğu virüsler de yer almaktadır. Bu virüsler antibiyotik direnç genlerini, toksin genlerini transdüksiyon ile aktarabilmektedirler (5).

İntestinal mikrobiyota dengesi, immün regülasyonu sağlayan mikrobiyal kompozisyonun dengede kalması ile yani simbiyoz ile sağlanır. Eğer mikrobiyota çeşitliliğinde azalma, değişiklik ya da bozulma olursa - ki bu disbiyoz olarak adlandırılır - alerji ve inflamasyonla giden immün disregülasyon meydana gelir (10). Yani insan sağlığının idamesinde gastrointestinal mikrobiyotanın klinik önemi büyüktür. Kardiyovasküler hastalık, obesite, tip 2 diyabet, non-alkolik yağlı karaciğer hastalığı (NAFLD) ve 
bazı kanser tipleri ile disbiyoz arasında ilişki olduğunu gösteren çalışmalar mevcuttur (11-18).

\section{Barsak mikrobiyomu ve kolorektal kanser}

Yüksek miktarda yağ ve kırmızı et, N-nitrazo bileşikleri ve heterosiklik aromatik aminlerin düzeyini arttırarak kansere yatkınlık oluşturur. Heterosiklik aminler hücrede DNA zedelenmesine yol açar. Barsak mikroorganizmalarından bazıları zedelenmeyi arttırır, bazıları bu bileşikleri metabolize ederek ortadan kaldırır. Hayvan çalışmalarında Bacteroides ve Clostridium türleri kolon tümör büyümesini hızlandırmakta; Lactobacilli ve Bifidobacteria türleri ise tümör gelişimini azaltmaktadırlar. Süperoksit oluşturan $E$. faecalis ve sülfat indirgeyen bakteriler epitel zedelenmesine yol açmaktadırlar. Bacteroides vulcatus ve $B$. stercoris varlığında kanser riski yüksek, Lactobacillus acidofilus fazla olan kişilerde ise düşük olarak gözlenmiştir (17-18).

\section{Barsak mikrobiyomu ve obesite}

Aynı diyetle beslenen, normal florası olan farelerin ağırığının, mikroorganizmalardan arındırılmış farelerin ağırlığından \%40 daha fazla olduğu saptanmıştır. Yemeklerin metabolize edilmesinde mikrobiyotanın önemli olduğu vurgulanmıştır (13). Bacteroides thetaiotaomicron, floranın baskın üyelerindendir ve başka yolla sindirilemeyen polisakkaritlerin sindirilmesini sağlayarak kalori gereksiniminin \%10-15'ini sağlamaktadır. Lactobacillus türleri ise safra asitlerinin bağlanmasını engelleyerek yağ emilimini azaltmaktadır. Şişman farelerin zayıf olanlara göre $\% 50$ daha az Bacteriodetes, \%50 daha fazla Firmicutes türlerini barsaklarında bulundurduğu saptanmıştır. Mikroorganizmadan arındırılmış farelere obez farelerin mikrobiyomu nakledildiğinde kilo aldıkları, antibiyotik ile tedavi edilen farelerde obezite ile birlikte Firmucutes'lerin Bacteroidetes'lere baskınlığı gözlenmiştir. Barsak mikrobiyomunun içeriğinin değişmesi ile SCFA'da azımsanmayacak artış ilişkisi de ortaya konulmuştur. SCFA kolon epitelinin doğrudan enerji sağlayıcısı ve portal sirkülasyona absorbsiyonu ile adipogenez stimülatörüdür. Obez bireylerin mezenterik yağ dokusunda, omentum ve diğer viseral yağ doku örneklerinde saptanmayan bakteri DNA örneklerine rastlanmıştır. $\mathrm{Bu}$ bakteri, Gram negatif bir basil olan, Proteobacter ailesinden Ralstonia picketti'dir.

Ralstonia pickettinin visseral dokuda varlığı ile sistemik inflamasyon arasında ve fekal düzeyi ile insülin direnci arasında pozitif korelasyon olduğu gösterilmiştir. Deneysel bir çalışmada, dört hafta süreyle $R$. picketti içeren gavaj alan ratlarda kilo alımının olduğu, oral glikoz tolerans testinin bozulduğu gösterilmiştir. Yine, bu etkene karşı geliştirilen aşı uygulanan ratlarda, insülin direncinin azaldığı gözlenmiştir (13-14).

\section{İnfantil kolik ve mikrobiyom}

Bebeklerin barsaklarının yavaş kolonize olması, mikrobiyal çeşitlilik ve stabilizasyonlarının az olması nedeniyle bu tablonun oluştuğu düşünülmektedir. İnfantil kolikli bebeklerde Lactobacillus ve Bifidobacterium türlerinin azaldığı, Clostridia ve Proteobacteria'ların arttığı gösterilmiştir (19-24).

\section{Barsak mikrobiyomu ve İnflamatuvar Barsak Hastalığı (IBBH)}

Son yıllarda IBH insidansında ciddi artış gözlenmektedir. Hastalık tek başına genetikle açıklanamamaktadır. Batıcı beslenme; artmış yağ ve kırmızı et tüketimi ile insidansında artış ilişkisi üzerinde durulmaktadır. Lifli gıdalar ve meyve tüketimi ile Crohn Hastalığı $(\mathrm{CH})$ sıklığında azalma, sebze tüketimi ile ülseratif kolitte azalma bildirilmiştir. Firmicutes'lerin özellikle Fecailbacterum prausnitzii'nin $\mathrm{CH}^{\prime} \mathrm{de}$ azaldığı, F. prausnitzii azalması ile post-operatif $\mathrm{CH}$ tekrarlaması arasında ilişki olduğu bildirilmiştir. İn-vitro ve hayvan çalışmalarında etkenin anti-inflamatuvar etkili olduğunu ve SCFA ve IL-10 artışına neden olduğunu gösterilmiştir. Erken yaşlarda az mikroorganizma ile karşılaşma, hayatının ileri döneminde karşılaşacağı mikrop yüklü çevreye toleransı azaltmakta ve uygunsuz immün yanıta neden olmaktadır (Hijyen teorisi). Aynı zamanda erken yaşta antibiyotik tüketimi, mikrobiyota çeşitliliğini azaltmakta ve IBH gelişim riskini arttırmaktadır $(17,25)$.

\section{Barsak mikrobiyomu ve hipertansiyon}

Esansiyel hipertansiyon etiyopatogenezinden mikrobiyata disbiyozisi sonucu oluşan tiramin aşırı üretiminin sorumlu olabileceği düşünülmektedir. İntestinal bakterilerin ürettiği aromatik-L-amino asit dekarboksilaz ile tirozin 
tiramine dönüşür. Lactobacillus bulgaricus histamin, tiramin ve triptamin, Enterococcus faecalis tiramin, Lactobacillus plantarum histamin ve tiramin üretirler. Anjiyotensin II ile uyarılmış hipertansif sıçanlarda Firmicutes ve Bacteroidetes oranında artış bildirilmiştir.

Insan mikrobiyotasını etkileyen faktörler; maternal kolonizasyon, yaş, diyet, çevresel temaslar ve antimikrobiyal tedavilerdir.

Çocukluk çağında antibiyotik kullanımı ve IBH gelişimi arasındaki ilişkiyi irdeleyen bir kohort çalışmada ilişki net olarak ortaya konulmuştur. Dünya antibiyotik kullanım haritası ile obesite haritası da benzerlikler göstermektedir. İlginç bir başka değerlendirme de dünya helmint enfestasyonları insidans haritası ile otoimmün bozukluk insidans haritasının karşılaştırılmasıyla elde edilmiştir. Helmint enfestasyonlarının yoğun olduğu ülkelerde, otoimmün olaylara daha az rastlandığı belirlenmiştir $(4-5,12)$.

\section{İnsan mikrobiyomu ve romatolojik hastalıklar}

İnsan mikrobiyomu, insan immüm sistemi ile tüm epitelyal yüzeylerde sıkı bir etkileşim içindedir. Genetik yatkınlığı olan bireylerde bazı kommensal bakteriler, inflamatuvar artritin potansiyel tetikleyicisi ve süreğenliğini sağlayıcı rol oynamaktadır. Mikrobiyomun spesifik elementlerindeki değişim disbiyoz ile sonuçlanır ve konak yanıtının anti-inflamatuvardan proinflamatuvara değişimine yol açar. Bu hipotez hayvan modelleriyle desteklenmiştir. Disbiyoza katkı sağlayan faktörler: genetik, diyet, yaşam şekli tercihi -sigara içmek gibi- ve potansiyel patojenik mikrooganizmalarla karşılaşma gibi faktörlerdir $(5,17)$.

Romatoid artrit (RA) etiyopatogenezinde periodontal patojenlerin rolü ile ilgili çalışmalar mevcuttur. RA hastalarında sağlıklı kontrollere göre daha fazla periodontit ve diş kaybı geliştiği, periodontal hastalığın şiddeti ile RA hastalık aktivitesinin ilişkili olduğu ve periodontit tedavisinin RA aktivitesini azalttığı bildirilmektedir. RA ve bazı spondiloartropati hastalarında sinoviyal sıvida oral mikrobiyota elemanlarının izolasyonu gösterilmiştir. Porphyromonas gingivalis ile RA ilişkisi literatürde güçlü bir şekilde gösterilmektedir. Bu etken endojen peptitleri (fibrinojen ve alfa enolaz peptitleri gibi) sitrüline eden peptidil arjinin deaminaz üretmekte ve RA hastalarında sitrüline proteinlere karşı antikor (anti-sitrülin protein antikoru- ACPA) artışı gösterilmektedir. Yine RA'lı hastalarda kommensal bakteri (Bifidobacterium, B. fragilis gibi) miktarında azalma gösterilmektedir (26-27).

Klebsiella pneumonia, Bacteroides vulgatus, sülfat üreten Disulfovibrio disulfuricans gibi bakterilerin spondiloartropati ve ülseratif kolit patogenezinden sorumlu olabileceği teorize edilmektedir (17-25).

\section{Mikrobiyota ilişkili tedaviler}

Probiyotikler, prebiyotikler, simbiyotikler ve fermentasyon ürünleri olan postbiyotiklerdir (28).

Probiyotikler: Uygun miktarda verilen canlı mikroorganizmalardır. Patojen mikroorganizma ile yarışmaya girerek, kolonun asitleştirilmesini engellerler. Biyoaktif molekül üretimi ve immünomodülasyonu sağlarlar. Lactobacillus türleri, Bifidobacterium türleri, Streptococcus salivarius, S. thermophilus, Enterococcus faecium, Escherichia coli, Clostridium butyricum ve Saccaromyces boulardii bu amaçla kullanılan probiyotiklerdendir

Prebiyotikler: Insan ve hayvanların barsak mikrobiyatasında bir veya daha fazla bakteri türünü seçici şekilde stimüle etme özelliğine sahip, sindirilmeyen besin maddeleri ya da kimyasallardırlar. En sık bilinenleri fruktooligosakkarit (FOS) ve galaktooligosakkarit (GOS)'tir. Bifidojenik olarak kabul edilen bu molekülleri kepek kaynakları, çiğ asparagus, muz, hindiba, soğan, sarımsak, pırasa gibi gıdalar içermektedirler. GOS/FOS karışımı ile hazırlanmış formül mamaları tüketen infantlarda bifidobakterlerin artı̆̆ı, patojen mikroorganizmaların azaldığı, gayta pH'sının azaldığı, sekretuvar ıgA'nın arttığı, atopik hastalıkların azaldığı, enfeksiyon oranlarının düştüğü ve dışkılama düzeninin iyileştiği gösterilmiştir.

Simbiyotikler: Prebiyotik ve probiyotiklerin beraber uygulanmasıdır.

Postbiyotikler: Göreceli olarak yeni bir terim olup, probiyotik bakterilerin (özellikle Bifidobacterium breve $\mathrm{C} 50$ ve Streptococcus thermophilus) metabolik ürünleridir (örneğin hidrojen peroksit). Çalışmalarda polio aşısına karşı IgA yanıtını arttırdığı, gastroenteriti önlediği, timüs boyutunu arttırdığı, inflamasyonu azalttığı, alerjiyi önlediği, 
infantta gastrointestinal semptomları azalttığına dair çalışmalar mevcuttur.

Tekrarlayan Clostridium difficile enfeksiyonlarında intestinal mikrobiyota transplantasyonu ise ilk kez 1958 yılında uygulanmıştır. Standart tedavinin başarısız olduğu durumlarda \%92 etkinliği olup, nazogastrik, nazojejunal, kolonoskopi ya da enema yoluyla uygulanabilmektedir. Transplantasyon öncesi antibiyotik kullanımının etkinliğini arttırdığı bildirilmiştir (29-30).

\section{Kaynaklar}

1. Lederberg J, McCray AT. Genealogical Treasury of Words. Scientist 2001; 15 (7): 8.

2. Kamada N, Seo SU, Chen GY, Nunez G. Role of the gut microbiota in immunity and inflammatory disease. Nat. Rev. Immunol 2013; 13: 321-35. 10.1038/nri3430.

3. Qin J, Li R, Raes J, et al. A human gut microbial gene catalogue established by metagenomic sequencing. Nature 2010; 464: 59-65. 10.1038/nature08821

4. Hansen TH, Gobel RJ, Hansen T, Pedersen O. The gut microbiome in cardio-metabolic health. Genome Med 2015; 7 (1): 33. doi: 10.1186/s13073-015-0157-z.

5. Kamo T, Akazawa $\mathrm{H}$, Suda $\mathrm{W}$, et al. Dysbiosis and compositional alterations with aging in the gut microbiota of patients with heart failure. PLoS One 2017; 12 (3): e0174099. 10.1371

6. Ley RE, Turnbaugh PJ, Klein S, Gordon JI. Microbial ecology: human gut microbes associated with obesity. Nature 2006; 444: 1022-3. 10.1038/4441022a

7. Wang Z, Klipfell E, Bennett BJ, et al. Gut flora metabolism of phosphatidylcholine promotes cardiovascular disease. Nature 2011; 472: 57-63. 10.1038/nature09922

8. Sommer F, Backhed F. The gut microbiota-masters of host development and phisiology. Nature Rev Microbiol 2013;11(4):227-38.

9. Pedersen HK, Gudmundsdottir V, Nielsen HB, et al. Human gut microbes impact host serum metabolome and insulin sensitivity. Nature 2016; 535: 376-81. 10.1038/nature18646

10. Henao-Mejia J, Elinav E, Jin C, et al. Inflammasome-mediated dysbiosis regulates progression of NAFLD and obesity. Nature 2012;482:179-85. 10.1038/nature10809

11. Tang WH, Kitai T, Hazen SL. Gut microbiota in cardiovascular health and disease. Circ Res 2017;120:1183-96. 10.1161/circresaha.117.309715

12. Emoto T, Yamashita T, Kobayashi T, et al. Characterization of gut microbiota profiles in coronary artery disease patients using data mining analysis of terminal restriction fragment length polymorphism: gut microbiota could be a diagnostic marker of coronary artery disease. Heart Vessels 2017; 32: 39-46. 10.1007/s00380-016-0841-y

13. Cani PD, Bibiloni R, Knauf $\mathrm{C}$, et al. Changes in gut microbiota control metabolic endotoxemiainduced inflammation in high-fat diet-induced obesity and diabetes in mice. Diabetes Metab Res Rev 2008;57:1470-81. 10.2337/db07-1403

14. Khan MT, Nieuwdorp M, Backhed F. Microbial modulation of insulin sensitivity. Cell Metab 2014;20:753-60. 10.1016/j.cmet.2014.07.006

15. Mouzaki M, Comelli EM, Arendt BM, et al. Intestinal microbiota in patients with nonalcoholic fatty liver disease. Hepatology 2013; 58: 120-27. 10.1002/hep.26319

16. Zhu L, Baker SS, Gill C, et al. Characterization of gut microbiomes in nonalcoholic steatohepatitis (NASH) patients: a connection between endogenous alcohol and NASH. Hepatology 2013; 57: 601-9. 10.1002/hep.26093

17. Gopalakrishnan V, Helmink BA, Spencer CN, Reuben A, Wargo JA. The influence of the gut microbiome on cancer, immunity, and cancer immunotherapy. Cancer Cell 2018; 33: 570-80. 10.1016/j.ccell.2018.03.015

18. Tilg H, Adolph TE, Gerner RR, Moschen AR. The intestinal microbiota in colorectal cancer. Cancer Cell 2018; 33: 954-64. 10.1016/j.ccell.2018.03.004 
19. Mullié $\mathrm{C}$, Yazourh $\mathrm{A}$, Thibault $\mathrm{H}$, et al. Increased poliovirus-specific intestinal antibody response coincides with promotion of Bifidobacterium longum-infantis and Bifidobacterium brevein infants: a randomized, double-blind, placebo-controlled trial. Pediatr Res 2004; 56: 791-5.

20. Thibault $\mathrm{H}$, Aubert Jacquin $\mathrm{C}$, Goulet $\mathrm{O}$. Effects of long-term consumption of a fermented infant formula (with Bifidobacterium breve c50 and Streptococcus thermophilus 065) on acute diarrhea in healthy infants. Journal of Pediatric Gastroenterology and Nutrition 39 (2): 147-52.

21. Anabrees J, Indrio F, Paes B, AlFaleh K. Probiotics for infantil colic: a systematic review. BMC Pediatr 2013; 13: 186. 1186/1471-2431-13-186.

22. Campeotto F, Suau A, Kapel N, et al. A fermented formula in pre-term infants: clinical tolerance, gut microbiota, down-regulation of faecal calprotectin and up-regulation of faecal secretory $\mathrm{lgA}$. $\mathrm{Br}$ J Nutr 2011; 28; 105 (12): 1843-51.

23. Morisset M, Aubert-Jacquin C, Soulaines P, Moneret-Vautrin DA, Dupont C. A non-hydrolyzed, fermented milk formula reduces digestive and respiratory events in infants at high risk of allergy. Eur J Clin Nutr 2011; 65 (2): 175-83.

24. Van de Heijning BJ, Berton A, Bouritius H, Goulet O. GI Symptoms in infants are a potential target for fermented infant milk formulae: a review. Nutrients 2014; 6 (9): 3942-67.

25. Kronman MP, Zaoutis TE, Haynes K, Feng R, Coffin SE. Antibiotic exposure and ibd development among children: a population-based cohort study. Pediatrics 2012; 130 (4): e794-e803.

26. Maeda, Yuichi, and Kiyoshi Takeda. "Role of Gut Microbiota in Rheumatoid Arthritis." Journal of clinical medicine vol. 6,6 60. 9 Jun. 2017, doi:10.3390/jcm6060060

27. Yuichi Maeda, Kiyoshi Takeda Host-microbiota interactions in rheumatoid arthritis. Experimental and Molecular Medicine volume 51, pages1-6(2019)

28. Chermesh Eliakim R. Probiotics and the gastrointestinal tract: Where are we in 2005? World J Gastroenterol 2006; 12: 853-7.

29. Report of a Joint FAO/WHO Expert Consultation on Evaluation of Health and nutrional properties of probiotics in food including powder milk with live lactic acid bacteria. Argentina 1-4 October 2001.

30. Gupta S, Allen-Vercoe E, Petrof EO. Fecal microbiota transplantation: in perspective. Therap Adv Gastroenterol. 2016; 9 (2): 229-239. doi:10.1177/1756283X15607414 